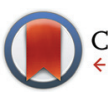

CrossMark \&lick for updates

Cite this: Dalton Trans., 2014, 43 12734

Received 19th May 2014

Accepted 20th June 2014

DOI: $10.1039 / c 4 d t 01459 f$

www.rsc.org/dalton

\section{Ruthenium(II) complexes containing functionalised $\beta$-diketonate ligands: developing a ferrocene mimic for biosensing applications $\uparrow$}

\author{
Yeng Ying Lee, D. Barney Walker, J. Justin Gooding* and Barbara A. Messerle* \\ Three series of ruthenium complexes with the general formula Ru(bpy) ( -diketonato $)_{3-n}$ (bpy $=2,2^{\prime}$ - \\ bipyridine, $n=0,1,2)$ were prepared and investigated using cyclic voltammetry and UV-vis spectroscopy. \\ Variation of both the number and electronic demand of the $\beta$-diketonato ligands resulted in well-defined \\ modulation of the potential at which oxidation of the metal centre occurred. The observed potentials were \\ shown to be in good agreement with calculated ligand electrochemical parameters. A novel ruthenium(॥) \\ complex with electrochemical behaviour similar to that of ferrocene was identified.
}

\section{Introduction}

Ferrocene is well established as an electrochemically active tag for investigating and monitoring biological activity in situ. ${ }^{1-9}$ This is largely due to the fact that, in addition to its favourable electrochemical properties, the ferrocenyl group can be readily functionalised and is considered to be relatively stable in aqueous, aerobic media. However, the ferricenium ion formed following oxidation has been shown to decompose when exposed to chloride ions, ${ }^{10-13}$ potentially limiting the application of ferrocene as a redox label in sensors designed for long-term analyte monitoring (e.g. implantable devices).

The stable and reversible nature of the $\mathrm{Ru}^{2+/ 3+}$ redox couple suggests that ruthenium complexes could be an attractive alternative to ferrocene for biological sensors and several groups have explored this possibility. ${ }^{14-22}$ An advantage of utilising ruthenium species is that the potential at which oxidation of the metal centre occurs can be influenced by the electronic demand of the ligands occupying the primary coordination sphere. Large changes in the $E_{1 / 2}$ of a $\mathrm{Ru}^{2+}$ centre can be induced either by introducing anionic ligands $\mathrm{s}^{23,24}$ and/ or by changing the number of $\pi$-acceptor coordinating species around the metal. ${ }^{25-30}$ More subtle 'tuning' of the redox potential has previously been demonstrated by attaching either electron-withdrawing or electron-donating groups (EWG or EDG) to the peripheral sites around the coordinating ligands..$^{28,31,32}$

School of Chemistry, The University of New South Wales, Sydney, NSW 2052, Australia.E-mail: b.messerle@unsw.edu.au, justin.gooding@unsw.edu.au; Fax: +61 2 93854161; Tel: +61 293854653

$\dagger$ Electronic supplementary information (ESI) available. See DOI: 10.1039/ c4dt01459f
Here we present the synthesis and electrochemical characterisation of three series of ruthenium complexes (of the general formulae $\left[\mathrm{Ru}(\mathrm{bpy})_{2}(\beta\right.$-diketonato $\left.)\right]\left(\mathrm{PF}_{6}\right),[\mathrm{Ru}(\beta$-diketonato $\left.)_{3}\right]$ and $\left[\mathrm{Ru}(\mathrm{bpy})(\beta \text {-diketonato })_{2}\right]$, bpy $=2,2^{\prime}$-bipyridine $)$ wherein the number and type of ligand is varied in order to tune the redox potential of the metal centre towards values suitable for biosensing applications. We take advantage of the fact that the potential at which oxidation of these ruthenium complexes occurs can be attenuated by varying the substituents on the $\beta$-diketonato ligands and identify several candidates for biosensor integration that have a very similar electrochemical profile to that of ferrocene.

\section{Results and discussion}

\section{Synthesis}

Three series of ruthenium complexes with $\beta$-diketonato ligands were prepared (Scheme 1) where the complexes of Series I each contains a single $\beta$-diketonato ligand, Series II, three $\beta$-diketonato ligands and Series III, two $\beta$-diketonato ligands.

Synthesis of Series I $\left[\mathrm{Ru}(\mathrm{bpy})_{2}(\boldsymbol{\beta}\right.$-diketonato $\left.)\right]\left(\mathrm{PF}_{6}\right)$ complexes. Ruthenium complexes 1-7 (Scheme 1a) were prepared using a method adapted from a literature procedure. ${ }^{33} \mathrm{Com}-$ pounds 1, 2 and 4 have been prepared previously (see ESI $\dagger$ for more information). ${ }^{34}$ All Series I complexes (excluding 4) were prepared by displacing chloride from $\mathrm{Ru}(\mathrm{bpy})_{2} \mathrm{Cl}_{2}$ with selected $\beta$-diketones in the presence of a stoichiometric amount of ${ }^{t} \mathrm{BuOK}$ in a hot EtOH- $\mathrm{H}_{2} \mathrm{O}$ mixture. The desired product was precipitated following cooling and the addition of an aqueous solution of $\mathrm{NH}_{4} \mathrm{PF}_{6}$ to the reaction mixture. Complex 4 was prepared by treatment of $\mathbf{1}$ with $\mathrm{N}$-bromosuccinimide in $\mathrm{CH}_{2} \mathrm{Cl}_{2}{ }^{35}$ 
a)
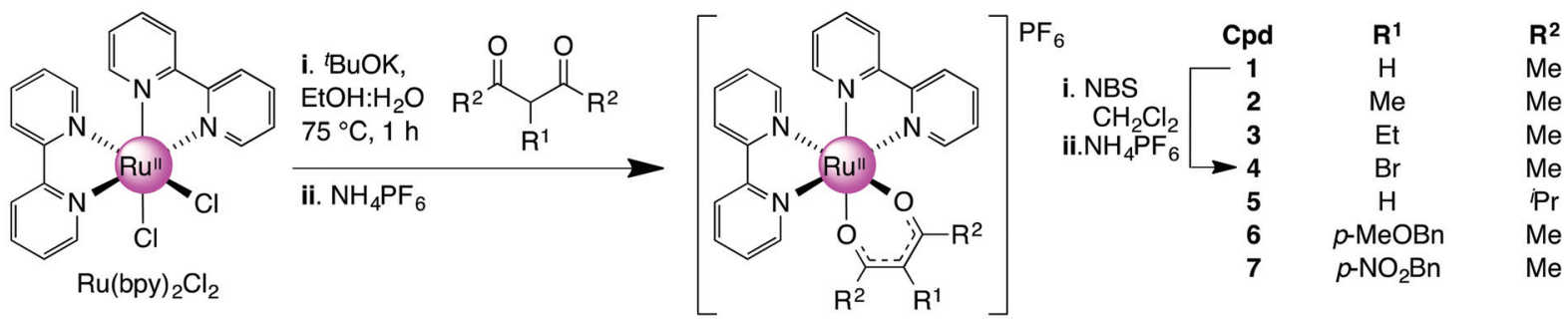

b)
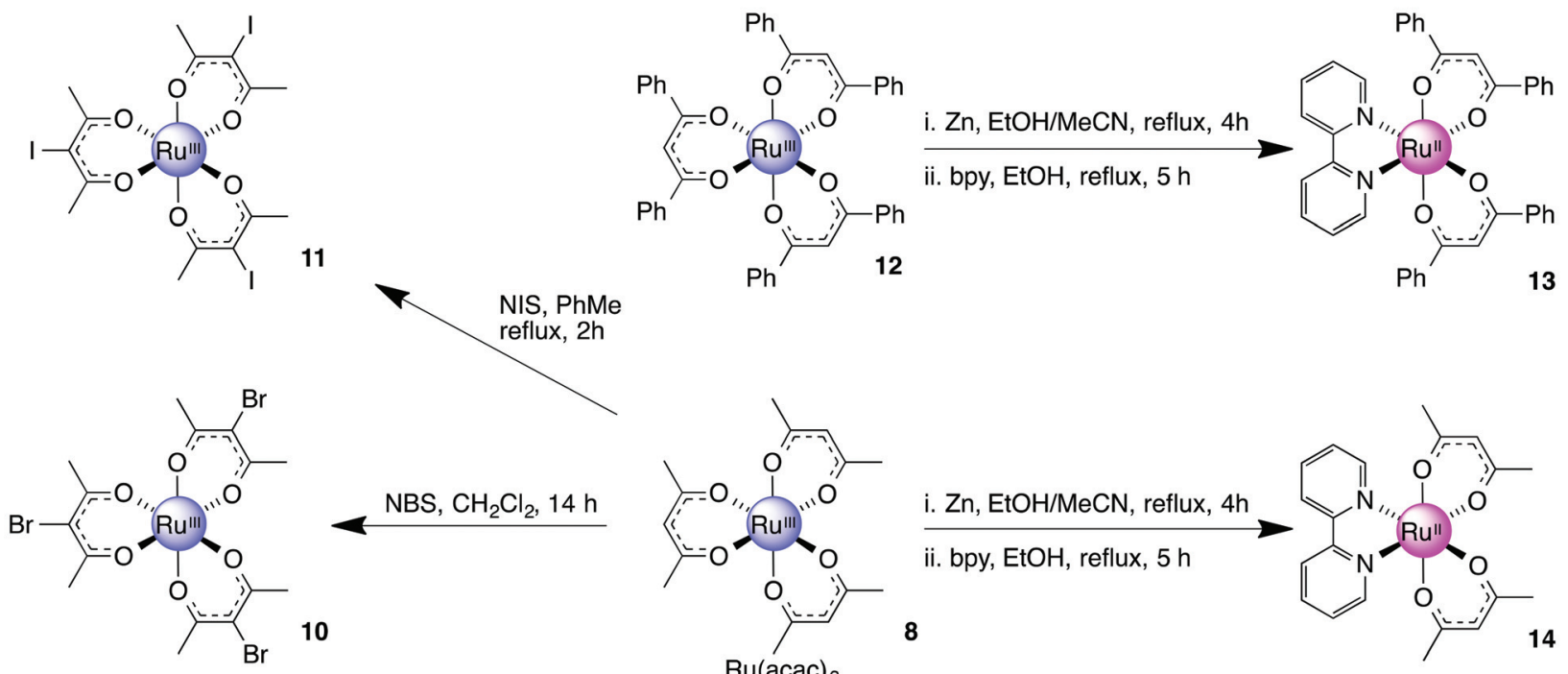

c)

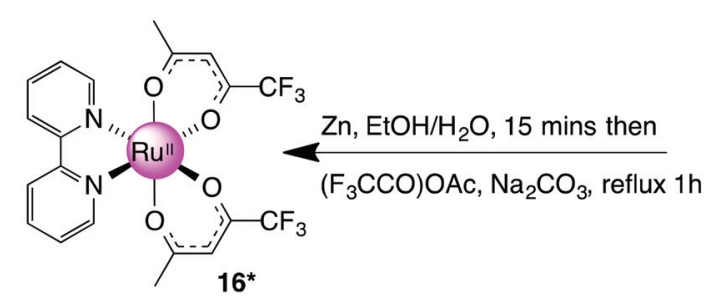

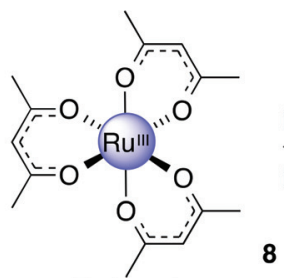

$\mathrm{Ru}(\mathrm{acac})_{3}$

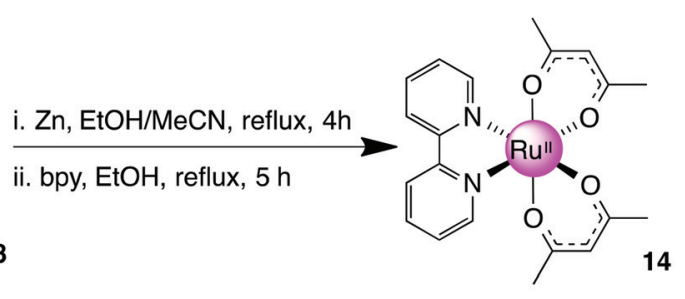

$\mathrm{Ac}_{2} \mathrm{O}, \mathrm{Cu}\left(\mathrm{NO}_{3}\right)_{2}$

$\checkmark$<smiles>CC1=C(C)OC2C(O1)OC(C)=C([N+](=O)[O-])OC21OC(C)=C(C)C(C)C([N+](=O)[O-])=C(C)O1</smiles>

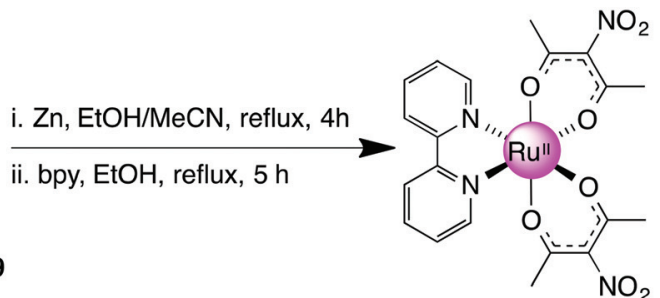<smiles></smiles>

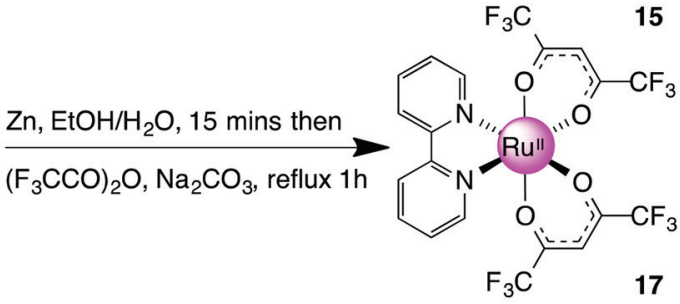

Scheme 1 Synthesis of complexes 1-17.

Novel compounds 5, 6 and 7 were prepared in the same way as compounds 1-4 in $60 \%, 53 \%$ and $27 \%$ yields respectively.

Synthesis of Series II $\left[\mathrm{Ru}(\beta \text {-diketonato })_{3}\right]$ complexes. Methods for the direct functionalisation of the acetylacetonate (acac) ligand of complex 8 have been described previously ${ }^{36,37}$ and these were utilised to expand the family of complexes investigated in this study. ${ }^{32,38-42}$ Following the method of Collman et al., ${ }^{42}$ nitration of 8 with $\mathrm{Cu}\left(\mathrm{NO}_{3}\right)_{2}$ in acetic anhydride was achieved to give $\mathrm{Ru}\left(\mathrm{NO}_{2} \text {-acac) }\right)_{3}$ (9) in $70 \%$ yield
(Scheme 1b). Complex 8 also underwent facile bromination with $\mathrm{N}$-bromosuccinimide to give $\mathrm{Ru}\left(\mathrm{Br}\right.$-acac) ${ }_{3}$ (10) in a $90 \%$ yield. ${ }^{32} \mathrm{Ru}(\mathrm{I} \text {-acac) })_{3}$ (11) was synthesised in the same way using $\mathrm{N}$-iodosuccinimide in $85 \%$ yield. Complex 12 was prepared in a $25 \%$ yield by following a literature procedure. ${ }^{28,31}$

Synthesis of Series III $\left[\mathrm{Ru}(\mathrm{bpy})(\boldsymbol{\beta} \text {-diketonato })_{2}\right]$ complexes. Due to the relatively substitution-inert nature of $\mathrm{Ru}(\beta$-diketonato $)_{3}$ complexes, one approach to the synthesis of the mixed $\beta$-diketonato and bpy complexes is to prepare an intermediate 
that allows clean ligand substitution reactions with bpy. ${ }^{43} \mathrm{Ru}-$ $(\beta \text {-diketonato })_{2}(\mathrm{MeCN})_{2}$ complexes were targeted as $\mathrm{MeCN}$ is sufficiently labile to be readily displaced by bpy. This method was originally applied to the synthesis of $\mathrm{Ru}(\mathrm{acac})_{2}$ (bpy) (14). ${ }^{44}$

Complex 13 was synthesised in two steps via a bis-acetonitrile $\left(\mathrm{Ru}(\mathrm{dbm})_{2}(\mathrm{MeCN})_{2}\right)(\mathrm{dbm}=$ dibenzoylmethane $)$ intermediate. This intermediate was accessed by the reduction of complex 12 with activated zinc dust in refluxing EtOH followed by cooling and the addition of excess MeCN. The mixture was then refluxed for a further $2 \mathrm{~h}$ resulting in a colour change from bright red to orange. ${ }^{45}$ Treatment of the intermediate $\left(\mathrm{Ru}(\mathrm{dbm})_{2}(\mathrm{MeCN})_{2}\right)$ with an equimolar amount of bpy in refluxing EtOH gave $\mathrm{Ru}(\mathrm{dbm})_{2}$ (bpy) (13) as a dark green solid in $60 \%$ yield. The methyl analogue $\left(\mathrm{R}^{2}=\mathrm{Me}\right)$ was prepared using the same procedure (8 was readily converted to 14 in a $60 \%$ overall yield). This method also proved successful for the preparation of nitro-analogue 15 but treatment of the tribromo/iodo ruthenium(III) complexes $(\mathbf{1 0}, \mathbf{1 1})$ with elemental zinc resulted in dehalogenation of the ruthenium species and instead formed 14 along with other decomposition products.

A second approach to preparing Series III complexes via $\mathrm{Ru}$ (bpy) $(\mathrm{Cl})_{4}$ was investigated concurrently. The starting material was obtained in $85 \%$ yield by dissolving $\mathrm{RuCl}_{3} \cdot 3 \mathrm{H}_{2} \mathrm{O}$ in dilute $\mathrm{HCl}$, adding 1.2 equiv. of bpy and then leaving the solution for 21 days at room temperature. ${ }^{46}$ Subsequent treatment of $\mathrm{Ru}(\mathrm{bpy})(\mathrm{Cl})_{4}$ with activated zinc dust in EtOH- $\mathrm{H}_{2} \mathrm{O}$ for $15 \mathrm{~min}$ followed by the addition of $\mathrm{Na}_{2} \mathrm{CO}_{3}$ and either 1,1,1-trifluoropentane-2,4-dione (tfac) or 1,1,1,5,5,5-hexafluoropentane-2,4dione (hfac) followed by refluxing for $1 \mathrm{~h}$ resulted in the formation of complexes 16 and 17 in 25\% and 33\% yields respectively (Scheme 1c). ${ }^{47}$ Complex 16 exists as a mixture of three geometrical isomers in 1:1:2 ratio of cis- and trans-isomers due to its asymmetric $\beta$-diketonato ligand. This was confirmed by ${ }^{1} \mathrm{H}$ NMR where the following configurations were observed: trans- $\mathrm{CF}_{3}-$ cis- $\mathrm{H}-\left[\mathrm{Ru}(\mathrm{tfac})_{2}\right.$ (bpy)], cis- $\mathrm{CF}_{3}-c i s-\mathrm{H}-\left[\mathrm{Ru}(\mathrm{tfac})_{2}(\mathrm{bpy})\right]$ and cis- $\mathrm{CF}_{3}$-trans-H-[Ru(tfac)$)_{2}$ (bpy)]. This is further supported by the presence of four signals in ${ }^{19} \mathrm{~F}$ NMR (see Experimental section).

Whilst this route initially appeared to be a more direct way of preparing $\mathrm{Ru}(\mathrm{bpy})(\beta \text {-diketonato })_{2}$ complexes compared with preforming the $\mathrm{Ru}(\beta \text {-diketonato })_{3}$ species first (Scheme $1 \mathrm{~b}$ ) our observation was that the overall yields tended to be significantly lower and in some cases the final product did not form at all. However this method did allow us to furnish sufficient amounts of complexes $\mathbf{1 6}$ and $\mathbf{1 7}$ for subsequent electrochemical analysis.

\section{Cyclic voltammetry}

All complexes in Series I-III were shown to undergo a redox cycle (assumed to be $\mathrm{Ru}^{2+/ 3+}$ ) with a peak separation $(\Delta E)$ between 59 to $95 \mathrm{mV}$, and $i_{\mathrm{pa}} / i_{\mathrm{pc}}$ at near unity indicating that the complexes were both electrochemically and chemically reversible. The $E_{1 / 2}$ of the complexes was independent of the scan rate $(\nu)$ and the redox processes were diffusion-controlled as $i_{\mathrm{p}} v s$. $\nu^{1 / 2}$ was found to be linear. Waves were assigned by comparison to those of analogous metal complexes. ${ }^{48}$
Table $1 E_{1 / 2}$ for Series I Ru(bpy) 2 ( $\beta$-diketonato) complexes

\begin{tabular}{lc}
\hline$\left.\left[\mathrm{Ru}(\mathrm{bpy})_{2}\left(\left(\mathrm{R}^{2} \mathrm{C}(\mathrm{O})\right)_{2} \mathrm{CR}^{1}\right)\right)\right] \mathrm{PF}_{6}$ & $E_{1 / 2}{ }^{a} / \mathrm{V}$ \\
\hline $\mathbf{1}\left(\mathrm{R}^{1}=\mathrm{H}, \mathrm{R}^{2}=\mathrm{Me}\right)$ & 0.228 \\
$\mathbf{2}\left(\mathrm{R}^{1}=\mathrm{Me}, \mathrm{R}^{2}=\mathrm{Me}\right)$ & 0.128 \\
$\mathbf{3}\left(\mathrm{R}^{1}=\mathrm{Et}, \mathrm{R}^{2}=\mathrm{Me}\right)$ & 0.181 \\
$\mathbf{4}\left(\mathrm{R}^{1}=\mathrm{Br}, \mathrm{R}^{2}=\mathrm{Me}\right)$ & 0.292 \\
$\mathbf{5}\left(\mathrm{R}^{1}=\mathrm{H}, \mathrm{R}^{2}=\mathrm{Pr}\right)$ & 0.201 \\
$\mathbf{6}\left(\mathrm{R}^{1}=p-\mathrm{MeOBn}^{2}=\mathrm{H}\right)$ & 0.167 \\
$7\left(\mathrm{R}^{1}=p-\mathrm{NO}_{2} \mathrm{Bn}, \mathrm{R}^{2}=\mathrm{H}\right)$ & 0.194 \\
${ }^{a} E_{1 / 2}$ vs. $\mathrm{FcH}^{+/ 0}$ in $0.01 \mathrm{M} \mathrm{AgNO}_{3}$ in $\mathrm{MeCN}^{-1}$ with $0.1 \mathrm{M} \mathrm{NBu}_{4} \mathrm{PF}_{6}$, \\
$\nu=0.1 \mathrm{~V} \mathrm{~s}^{-1}$.
\end{tabular}

Series I. Ruthenium(II) complexes 1-7 $\left[\mathrm{Ru}(\mathrm{bpy})_{2}(\boldsymbol{\beta}\right.$-diketonato) $]\left(\mathbf{P F}_{\mathbf{6}}\right)$. The potential at which oxidation of the ruthenium(II) complexes occurs in Series I (compounds $\mathbf{1}$ to 7 ) were observed to be subtly influenced by the various substituents on the $\beta$-diketonato ligands. Complex 2 has an electron-donating methyl group at the methine position $\left(\mathrm{R}^{1}=\mathrm{Me}\right.$, Scheme 1a). Consequently, a cathodic shift of the redox potential of 2 by $100 \mathrm{mV}(128 \mathrm{mV}$ vs. $228 \mathrm{mV}$ ) was observed when compared with that of complex 1 (Table 1). A similar cathodic shift was observed for the redox potential of $3\left(\mathrm{R}^{1}=\mathrm{Et}\right)$ although in this case the change is less pronounced $\left(\Delta E_{1 / 2}=\right.$ $47 \mathrm{mV}$ ) in line with the reduced electron donating capacity of the ethyl groups of 3 compared with the methyl groups of 2 . These observations are in agreement with previous reports ${ }^{49}$ and can be rationalised as follows: an electron-donating group (EDG) on the $\beta$-diketonato ligand increases the electron density around the metal centre and consequently destabilises electrons in the metal d-orbitals. Thus the metal centre is more readily oxidised resulting in the observed cathodic shift in the $E_{1 / 2}$.

By the same argument, introducing an electron-withdrawing group (EWG) should result in an anodic shift in the $E_{1 / 2}$ and this effect was observed for complex $4\left(\mathrm{R}^{1}=\mathrm{Br}\right)$ when compared with $1\left(\Delta E_{1 / 2}=64 \mathrm{mV}\right)$.

As expected, complex $5\left(\mathrm{R}^{2}={ }^{\mathrm{i}} \mathrm{Pr}\right)$ and complex $1\left(\mathrm{R}^{2}=\mathrm{Me}\right)$ had almost identical electrochemical profiles $\left(\Delta E_{1 / 2}=27 \mathrm{mV}\right)$. The potentials at which complexes 6 and 7 were oxidised are quite similar (167 mV and $194 \mathrm{mV}$ respectively) despite having functional groups with quite different electronic demands in the para position of the benzyl group (OMe vs. $\left.\mathrm{NO}_{2}\right)$. This is not surprising considering that the aromatic ring is not in direct conjugation with the diketonate portion of the ligand bound to the ruthenium(II) ion. Consequently a modest cathodic shift $\left(\Delta E_{1 / 2}=61 \mathrm{mV}\right.$ for $6, \Delta E_{1 / 2}=34 \mathrm{mV}$ for 7$)$ is observed in both cases due to the slight electron donating effect of the benzylic $\mathrm{CH}_{2}$ group.

Series II and III. Ruthenium(II) complexes 8-17, Ru ( $\beta$-diketonato $)_{3}$ vs. $\left[\mathbf{R u}(\mathbf{b p y})(\boldsymbol{\beta} \text {-diketonato })_{2}\right]\left(\mathbf{P F}_{\mathbf{6}}\right)$. The potentials at which all the Series II complexes (8-12) oxidised were all shifted cathodically compared with those of Series I due to the presence of three anionic ligands. In addition, as with Series I, the effect of a strongly EWG $\left(\mathrm{R}^{1}=\mathrm{NO}_{2}, 9\right)$ results in a large anodic shift $(671 \mathrm{mV})$ of the potential at which the complex 
Table $2 E_{1 / 2}$ for Series II and III complexes

\begin{tabular}{|c|c|}
\hline Series II & $E_{1 / 2}{ }^{a} / \mathrm{V}$ \\
\hline 8 (acac) & -1.06 \\
\hline $9\left(\mathrm{NO}_{2}-\mathrm{acac}\right)$ & -0.389 \\
\hline 10 (Br-acac) & -0.830 \\
\hline $\mathbf{1 1}^{b^{b}}(\mathrm{I}-\mathrm{acac})$ & -0.829 \\
\hline $12(\mathrm{dbm})$ & -0.906 \\
\hline Series III & $E_{1 / 2}{ }^{a} / \mathrm{V}$ \\
\hline 13 (dbm) & -0.416 \\
\hline 14 (acac) & -0.478 \\
\hline $15\left(\mathrm{NO}_{2}-\mathrm{acac}\right)$ & -0.054 \\
\hline 16 (tfac) & -0.087 \\
\hline 17 (hfac) & 0.395 \\
\hline
\end{tabular}

oxidised when compared with 8 . The halogenated analogues of $\mathrm{Ru}(\mathrm{acac})_{3}$ (10 and 11) were also found to have an anodically shifted $E_{1 / 2}$ although the effect was less significant $\left(\Delta E_{1 / 2}=\right.$ $230 \mathrm{mV}$ for $\mathrm{Br}, 231 \mathrm{mV}$ for I). The potential at which complex 12 was oxidised was relatively close to that of $\mathbf{8}$ despite having six phenyl rings conjugated with the coordinating oxygen atoms (Table 2).

It might be expected that moving from Series II to Series III compounds, wherein one $\beta$-diketonato ligand is substituted for a bpy ligand, would result in a set of complexes with an $E_{1 / 2}$ closer to the desired redox window $(-0.743 \mathrm{~V}$ to $+0.067 \mathrm{~V}$ vs. $\mathrm{FcH}^{+/ 0},-0.343 \mathrm{~V}$ to $+0.467 \mathrm{~V}$ vs. $\left.\mathrm{Ag} / \mathrm{AgCl}\right)$.

The replacement of a $\beta$-diketone in $\mathbf{1 2}$ and $\mathbf{8}$ by bpy to form 13 and 14 raised the $E_{1 / 2}$ by $490 \mathrm{mV}$ and $672 \mathrm{mV}$ respectively. This was attributed to the fact that bpy is a $\pi$-acceptor - and the HOMO-LUMO gap of the complex could be increased and may result in a more stabilised $\mathrm{Ru}^{2+}$ complex. The stabilising effect of bpy works in concert with the $\mathrm{NO}_{2}$-acac ligands used to form 15 resulting in an observed $E_{1 / 2}$ of $-54 \mathrm{mV}\left(v s . \mathrm{FcH}^{+/ 0}\right)$. In the same way it was possible to anodically shift the potential at which the ruthenium metal centre is oxidised by replacing the acac ligands with tri- and hexafluorinated 2,4-diones. A comparison of the $E_{1 / 2} \mathrm{~S}$ of $\mathbf{1 6}$ with $\mathbf{1 4}$ demonstrates this effect $\left(\Delta E_{1 / 2}=391 \mathrm{mV}\right)$. The potential at which 17 oxidised was anodically shifted by $482 \mathrm{mV}$ compared to that of 16. This difference corresponds to the number of trifluoromethyl substituents on the ligands: there are four in $\mathbf{1 7}$ compared to two in 16. Of the Series III complexes, 15 and $\mathbf{1 6}$ were each shown to have an $E_{1 / 2}$ very close to that of ferrocene $\left(E_{1 / 2}=-54 \mathrm{mV}\right.$ and $-87 \mathrm{mV}$ respectively).

\section{Diffusion coefficient, $D_{\mathrm{o}}$}

The diffusion coefficients, $D_{\mathrm{o}}$, of complexes 1-17 in acetonitrile were obtained using the Randles-Sevcik equation:

$$
i_{\mathrm{p}}=2.69 \times 10^{5} n^{3 / 2} A D_{\mathrm{o}}{ }^{1 / 2} C \nu^{1 / 2}
$$

Table 3 Diffusion coefficients for ruthenium complexes in Series I and III

\begin{tabular}{ll}
\hline Series I & $D_{\mathrm{o}} / 10^{-9} \mathrm{~m}^{2} \mathrm{~s}^{-1}$ \\
\hline $\mathbf{1}\left(\mathrm{R}^{1}=\mathrm{H}, \mathrm{R}^{2}=\mathrm{Me}\right)$ & 1.759 \\
$\mathbf{2}\left(\mathrm{R}^{1}=\mathrm{Me}, \mathrm{R}^{2}=\mathrm{Me}\right)$ & 1.489 \\
$\mathbf{3}\left(\mathrm{R}^{1}=\mathrm{Et}, \mathrm{R}^{2}=\mathrm{Me}\right)$ & 1.182 \\
$\mathbf{4}\left(\mathrm{R}^{1}=\mathrm{Br}, \mathrm{R}^{2}=\mathrm{Me}\right)$ & 1.330 \\
$\mathbf{5}\left(\mathrm{R}^{1}=\mathrm{H}, \mathrm{R}^{2}=\mathrm{i} \mathrm{Pr}\right)$ & 1.561 \\
$\mathbf{6}\left(\mathrm{R}^{1}=p-\mathrm{MeOBn}, \mathrm{R}^{2}=\mathrm{H}\right)$ & 1.495 \\
$7\left(\mathrm{R}^{1}=p-\mathrm{NO}_{2} \mathrm{Bn}, \mathrm{R}^{2}=\mathrm{H}\right)$ & 1.346 \\
\hline
\end{tabular}

Series III

$13(\mathrm{dbm})$

14 (acac)

0.100

$15\left(\mathrm{NO}_{2}\right.$-acac $)$

1.354

16 (tfac)

0.645

17 (hfac)

1.369

where $i_{\mathrm{p}}=$ current, $n=$ number of electrons transferred, $A=$ electrode area, $D=$ diffusion coefficient, $C=$ bulk concentration of redox species and $\nu=$ scan rate (Table 3 ).

The electrode area on the glassy carbon electrode, A, was determined using the known $D_{\mathrm{o}}$ of ferrocene in acetonitrile with $0.1 \mathrm{M} \mathrm{NBu} \mathrm{PF}_{6}$ as a supporting electrolyte $(2.24 \times$ $\left.10^{-5} \mathrm{~cm}^{2} \mathrm{~s}^{-1}\right) .{ }^{50}$

Complexes with bulky ligands, and those of higher charge, would be expected to have smaller $D_{\mathrm{o}}$ values as they would be expected to migrate more slowly in solution. ${ }^{15,51,52}$ Additionally, changes in electron density around ruthenium brought on by donor/acceptor groups on $\beta$-diketonates will affect the degree to which counterions will attach to the reduced complexes. ${ }^{53}$ The structurally simplest complex in Series I, 1, has the largest $D_{\mathrm{o}}$ while the rest of the complexes are between 1.182 to $1.561 \times 10^{-9} \mathrm{~m}^{2} \mathrm{~s}^{-1}$. However, the bulkiest complex of the series did not have the smallest $D_{\mathrm{o}}$. This could be attributed to the interaction between these charged complexes of Series I with acetonitrile and the supporting electrolytes.

In Series III, the $D_{\mathrm{o}}$ for 13, which contains the bulkiest ligand, dbm, is about one order of magnitude smaller than that of $\mathbf{8}$. In the same way complex 17, with two trifluoromethyl groups on each $\beta$-diketonato ligand, has a smaller $D_{\mathrm{o}}$ than $\mathbf{1 6}$ which only has one trifluoromethyl group on each ligand. Complex 15 has a lower $D_{\mathrm{o}}$ when compared to 16 and 17, which can possibly be attributed to its interaction with the supporting electrolyte as the nitro group, although formally neutral, has considerable polarisation between its nitrogen and oxygen atoms.

\section{Relationships between the nature of the ligands and $E_{1 / 2}$}

The ruthenocycle formed by the coordination of acac-type ligands to $\mathrm{Ru}$ cations can be considered pseudo-aromatic. As such, the Hammett constant can be used to correlate the combined electronic effects of 'para' and 'meta' substituents on the $\beta$-diketonates with the potential at which the metal centres oxidised on the basis that such complexes can be thought of as having similar geometries and a common redox centre, for 


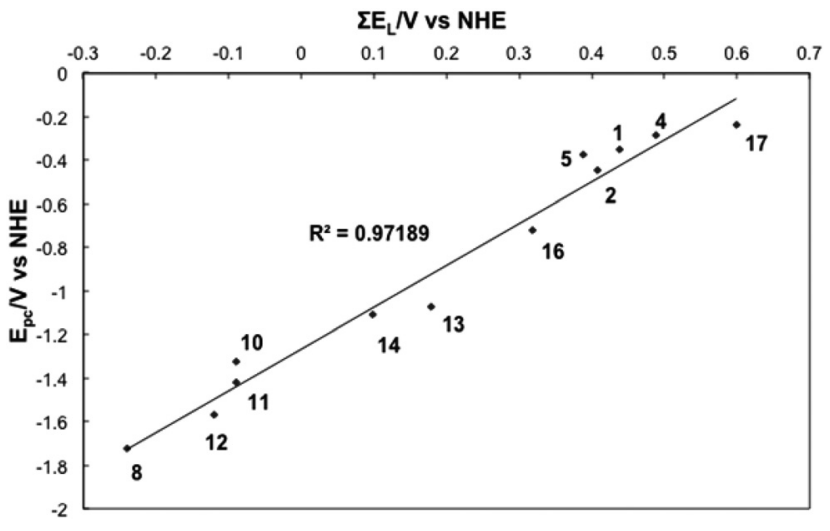

Fig. $1 \sum E_{(\mathrm{L})}$ vs. $E_{1 / 2}$ for selected complexes.

which linear free energy relationships can be established. ${ }^{54-56}$ In this study correlation of the calculated Hammett constants with the recorded $E_{1 / 2} \mathrm{~S}$ is limited by the fact that the contribution of the bpy ligands is not included. Consequently, a reasonably linear correlation was observed for Series II and III but not for Series I (see ESI†े).

Instead a more comprehensive method for probing the relationship between the structural and electronic features of a complex and its redox potential was applied. ${ }^{57}$ The most commonly utilised additive model was originally developed by Lever $^{58}$ and has proved to be a useful tool for investigating metal-centred redox processes. The ligand electrochemical parameter, $E_{\mathrm{L}}(\mathrm{L})$, used in this model and based on the $\mathrm{Ru}^{2+/ 3+}$ redox couple, has been widely applied to examine the correlation between ligands and $E_{1 / 2}$ of metal complexes. For a metal $(\mathrm{M})$ centre bound to multiple varying ligands $\left(\mathrm{X}_{x}, \mathrm{Y}_{y}, \mathrm{Z}_{z}\right)$, $E_{\mathrm{L}}(\mathrm{L})$ is defined as:

$$
\sum E_{(\mathrm{L})}=x E_{\mathrm{L}}(\mathrm{X})+y E_{\mathrm{L}}(\mathrm{Y})+z E_{\mathrm{L}}(\mathrm{Z}) .
$$

This formula can be used to predict the $E_{1 / 2}$ of complexes with an octahedral geometry. ${ }^{58}$

The $\sum E_{(\mathrm{L})}$ was calculated for all complexes in Series I-III where values for $E_{(\mathrm{L})}(\mathrm{L})$ were available (Table S4). A strongly linear correlation was established between $E_{(\mathrm{L})}(\mathrm{L})$ and $E_{1 / 2}$ of the complexes of Series I-III suggesting that the ligand contributions are additive (Fig. 1).

\section{Correlation between UV-Vis absorbance and $E_{1 / 2}$}

UV-vis spectra of complexes 1-7 (Series I) were recorded in $\mathrm{MeCN}$ at a concentration of $0.05 \mathrm{mM}$ and the data is summarised in Table 4. In total, there are two strong absorption bands assigned to $\pi \rightarrow \pi^{*}$ intraligand transitions in the UV region and three MLCT bands $\mathrm{d} \pi\left(\mathrm{Ru}^{2+}\right) \rightarrow \pi^{*}(\mathrm{~L})(\mathrm{L}=$ bpy, $\beta$-diketonate) in the visible region. For complexes 1-3 the data reported here is in agreement with literature values. ${ }^{48,59,60}$ The UV-vis spectrum for complex $4\left(\mathrm{R}^{1}=\mathrm{Br}, \mathrm{R}^{2}=\mathrm{Me}\right)$ shows a slight hypsochromic shift in the MLCT bands (504 vs. $515 \mathrm{~nm}, 558$ vs. $568 \mathrm{~nm}$ ) when compared with those of $\mathbf{1}$ that could be indicative of an increased HOMO-LUMO gap. This is in agreement with the electrochemical data as a notably higher potential is required
Table 4 Absorption maxima, $\lambda_{\max }$, and molar extinction coefficients, $\varepsilon$ for Series I

\begin{tabular}{ll}
\hline Complex & $\lambda / \mathrm{nm}\left(\varepsilon / 10^{3} \mathrm{M}^{-1} \mathrm{~cm}^{-1}\right)$ \\
\hline $\mathbf{1}\left(\mathrm{R}^{1}=\mathrm{H}, \mathrm{R}^{2}=\mathrm{Me}\right)$ & $247(28.4), 295(53.8), 369(11.3), 515(9.3)$, \\
$\mathbf{2}\left(\mathrm{R}^{1}=\mathrm{Me}, \mathrm{R}^{2}=\mathrm{Me}\right)$ & $568 \mathrm{sh}(6.1)$ \\
& $247(22.9), 296(46.5), 374(10), 521(7.5)$, \\
$\mathbf{3}\left(\mathrm{R}^{1}=\mathrm{Et}, \mathrm{R}^{2}=\mathrm{Me}\right)$ & $586 \operatorname{sh}(5.1)$ \\
& $247(26.0), 295(5.9), 373(11.2), 519(10.4)$, \\
$\mathbf{4}\left(\mathrm{R}^{1}=\mathrm{Br}, \mathrm{R}^{2}=\mathrm{Me}\right)$ & $580 \mathrm{sh}(5.6)$ \\
$\mathbf{5}\left(\mathrm{R}^{1}=\mathrm{H}, \mathrm{R}^{2}={ }^{\mathrm{i}} \mathrm{Pr}\right)$ & $246(23.8), 294(53.6), 370(10.7), 504(8.3)$, \\
$\mathbf{6}\left(\mathrm{R}^{1}=p-\mathrm{MeOBn}, \mathrm{R}^{2}=\mathrm{H}\right)$ & $248 \mathrm{sh}(5.5)$ \\
& $2476(25.2), 295(47.8), 370(10.2), 516(7.7)$, \\
$7\left(\mathrm{R}^{1}=p-\mathrm{NO}_{2} \mathrm{Bn}, \mathrm{R}^{2}=\mathrm{H}\right)$ & $247 \mathrm{sh}(5.7), 295(51.1), 376(11.2), 518(8.0)$, \\
& $575 \mathrm{sh}(4.1), 295(42.1), 373(8.5), 512(5.9)$,
\end{tabular}

Table 5 Absorption maxima, $\lambda_{\max }$, and molar extinction coefficients, $\varepsilon$ for Series III complexes

\begin{tabular}{ll}
\hline Complex & $\lambda / \mathrm{nm}\left(\varepsilon / 10^{3} \mathrm{M}^{-1} \mathrm{~cm}^{-1}\right)$ \\
\hline $\mathbf{1 3}(\mathrm{dbm})$ & $246(28.8), 300(34.8), 323(31.2), 485(9.0), 608(7.5)$ \\
$\mathbf{1 4}(\mathrm{acac})$ & $277 \mathrm{sh}(24.5), 297(17.5), 411(8.8), 617(4.9)$ \\
$\mathbf{1 5}\left(\mathrm{NO}_{2}\right.$-acac) & $249(14.8), 287(19.7), 297(21.0), 408(8.5), 546(5.14)$ \\
$\mathbf{1 6}(\mathrm{tfac})$ & $248(15.0), 287 \mathrm{sh}(27.5), 294(25.4), 425(7.7), 559(6.7)$ \\
$\mathbf{1 7}(\mathrm{hfac})$ & $243(6.5), 289(16.2), 337(1.6), 509(5.6)$
\end{tabular}

to oxidise the $\mathrm{Ru}(\mathrm{II})$ metal centre of $4\left(E_{1 / 2}=292 \mathrm{mV}\right)$ when compared with $1\left(E_{1 / 2}=228 \mathrm{mV}\right)$. Overall, the absorbance spectra of all Series I complexes are dominated by the influence of the anionic $\beta$-diketonato ligand and are consequently very similar to each other (see Fig. $\mathrm{S} 4 \dagger$ for spectra). ${ }^{61}$

In contrast to Series I, the UV-vis absorption spectra of complexes in series III are markedly different from each other (Table 5). The absorptions due to the four phenyl rings attached to complex $\mathbf{1 3}$ are clearly visible in the UV-vis spectrum at $246 \mathrm{~nm}$. These additional aromatic groups may also account for the broad band observed around $300 \mathrm{~nm}$ which could result from a degree of overlapping with the $\pi \rightarrow \pi^{*}$ intraligand transitions of bpy.

The spectrum for complex 15 contains significant distortion of the band at around $300 \mathrm{~nm}$ where no clear maximum is visible. This could be attributed to an overlap of the nitro group absorption with the $\mathrm{t}_{2 \mathrm{~g}} \rightarrow \pi^{*}$ (MLCT) band. ${ }^{62}$ The strongly electron-withdrawing nitro group may also account for the significantly blue-shifted MLCT maxima observed at $546 \mathrm{~nm}$.

Both 16 and 17 contain strongly electron-withdrawing trifluoromethyl groups on the $\beta$-diketonato ligands. In line with this, the spectrum of complex 16 contains a MLCT band at $559 \mathrm{~nm}$ whereas the corresponding peak for $\mathbf{1 7}$ appears at $509 \mathrm{~nm}$ (Fig. 2 and 3).

\section{Conclusions}

In this paper, ruthenium complexes bearing bpy and $\beta$-diketonato ligands were prepared, fully characterised and investi- 


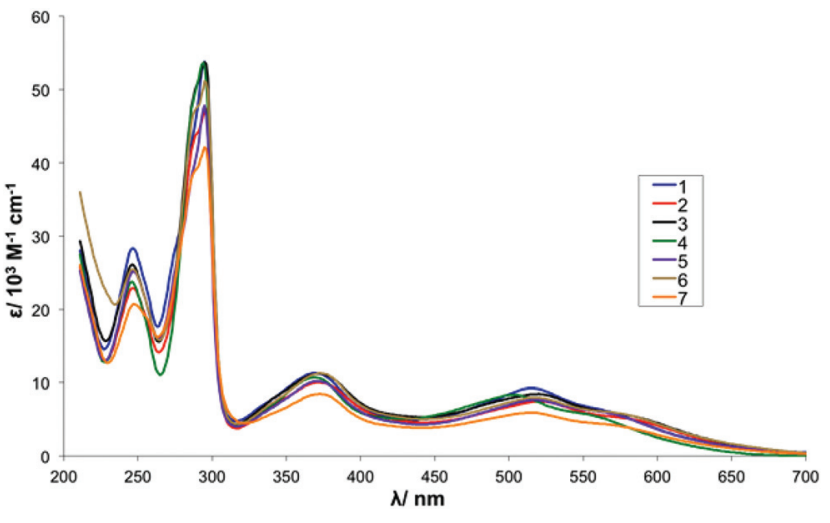

Fig. 2 UV-Vis absorbance spectra for complexes 1-7.

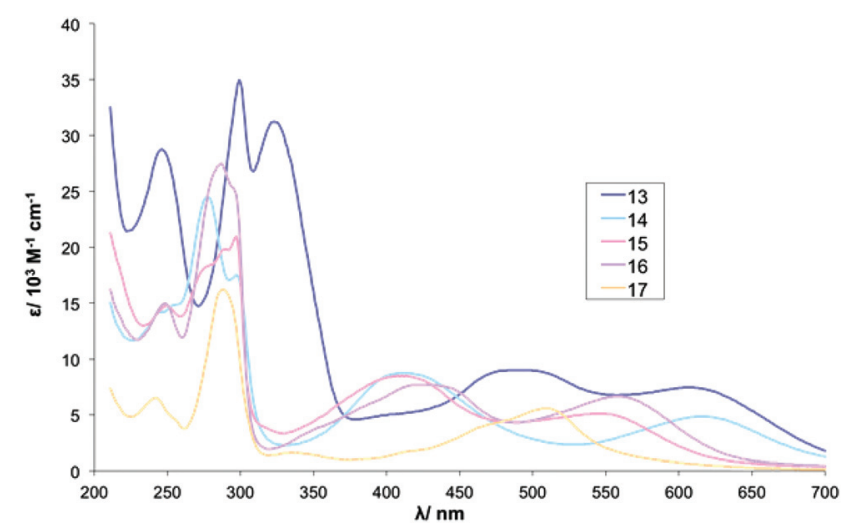

Fig. 3 UV-Vis absorbance spectra for complexes 13-17.

gated using cyclic voltammetry and UV-vis spectroscopy. Three series of ruthenium complexes were investigated: Series I (1-7) of the general formula $\left[\mathrm{Ru}(\mathrm{bpy})_{2}(\beta\right.$-diketonato $\left.)\right]\left(\mathrm{PF}_{6}\right)$; Series II (8-12) of the general formula $\mathrm{Ru}(\beta \text {-diketonato })_{3}$ and Series III (13-17) of the general formula $\mathrm{Ru}(\mathrm{bpy})(\beta \text {-diketonato })_{2}$. In line with previous studies, varying the substituents tethered to the $\beta$-diketonato ligand attenuated the $E_{1 / 2}$ of the complexes. It was observed that EDG shifted the $E_{1 / 2}$ cathodically whereas EWG shifted the $E_{1 / 2}$ anodically. Furthermore the effects were shown to be cumulative based on the number of $\beta$-diketonato ligands bound to the metal centre. Further correlations were made between $E_{1 / 2}$ of complexes and the ligand electrochemical parameter $\left(\sum E_{(\mathrm{L})}\right)$. The ligand electrochemical parameter was shown to have a linear relationship with $E_{1 / 2}$ for all three series.

Of the complexes prepared, the $E_{1 / 2}$ of complexes 7, 13, 14, 15 and 16 were demonstrated to have $E_{1 / 2} \mathrm{~S}$ within the range considered suitable for biological sensors $(-0.743 \mathrm{~V}$ to $+0.067 \mathrm{~V}$ vs. $\left.\mathrm{FcH}^{+/ 0}\right)$. Furthermore, the novel complex 15 and the previously reported complex 16 were demonstrated each to have an $E_{1 / 2}$ very close to that of ferrocene $\left(E_{1 / 2}=-54 \mathrm{mV}\right.$ and $-87 \mathrm{mV}$ vs. $\mathrm{FcH}^{+/ 0}$, respectively) suggesting that they would be also good candidates for redox labels in electroactive biosensors.

\section{Experimental methods}

All manipulations of metal complexes and air sensitive reagents were performed using either standard Schlenk techniques or in a nitrogen/argon filled Braun glove-box. Reagents were purchased from Aldrich Chemical Company Inc. or Alfa Aesar Inc. and were used without further purification unless otherwise stated. For the purposes of air sensitive manipulations and in the preparation of air sensitive complexes, pentane, hexane, dichloromethane and tetrahydrofuran were dispensed from a PuraSolv solvent purification system. Solvents were dried and distilled under an atmosphere of nitrogen using standard procedures and stored under nitrogen in glass ampoules, each fitted with a Youngs ${ }^{\circledR}$ Teflon valve prior to use. Ethanol (EtOH) was distilled from diethoxymagnesium and dimethylformamide (DMF) was first dried over molecular sieves (4 Å) and distilled. Argon (>99.999\%) was obtained from Air Liquide and used as received. Nitrogen gas for Schlenk line operation comes from in-house liquid nitrogen boil-off. ${ }^{1} \mathrm{H}$ and ${ }^{13} \mathrm{C}$ NMR spectra were recorded on Bruker DPX300, DMX400, DMX500 and DMX600 spectrometers operating at $300,400,500$ and $600 \mathrm{MHz}\left({ }^{1} \mathrm{H}\right)$ respectively and $75,100,125$ and $150 \mathrm{MHz}\left({ }^{13} \mathrm{C}\right)$ respectively. Unless otherwise stated, spectra were recorded at $25{ }^{\circ} \mathrm{C}$ and chemical shifts $(\delta)$ are quoted in ppm. Coupling constants $(J)$ are quoted in $\mathrm{Hz}$ and have uncertainties of $\pm 0.05 \mathrm{~Hz}$ for ${ }^{1} \mathrm{H}$ and $\pm 0.5 \mathrm{~Hz}$ for ${ }^{13} \mathrm{C}$. ${ }^{1} \mathrm{H}$ and ${ }^{13} \mathrm{C}$ NMR chemical shifts were referenced internally to residual solvent resonances. Deuterated solvents were purchased from Cambridge Stable Isotopes and used as received. Microanalyses were carried out at the Campbell Micro-analytical Laboratory, University of Otago, New Zealand or at the Research School of Chemistry, the Australian National University, Canberra, Australia. Mass spectra were acquired using a Thermo LTQ Orbitrap XL located in the Bio-analytical Mass Spectrometry Facility (BMSF) of the Mark Wainwright Analytical Centre, UNSW or on a Micromass ZQ (ESI-MS) mass spectrometer located in the School of Chemistry, UNSW. $M$ is defined as the molecular weight of the compound of interest or cationic fragment for cationic metal complexes.

Cyclic voltammetry was performed using an Autolab PGSTAT 12 potentiostat (Eco Chemie, Netherlands). The CV data was processed using Nova Windows software. A conventional three-electrode electrochemical cell comprised of a working electrode (glassy carbon), a counter electrode (platinum wire) and a reference electrode (aqueous or nonaqueous depending on the solvent system of the experiment) was used for all analysis. The aqueous reference electrode was a $\mathrm{Ag} / \mathrm{AgCl}(3 \mathrm{M} \mathrm{KCl})$ electrode (CH Instruments, Inc., TX, USA) while the non-aqueous reference electrode was a $\mathrm{Ag} / \mathrm{Ag}^{+}$electrode (CH Instruments, Inc., TX, USA) which was referenced against ferrocene. The working electrodes used were glassy carbon electrodes ( $\mathrm{CH}$ Instruments, Inc., TX, USA). The solutions for electrochemical measurements were deoxygenated with nitrogen gas for $10 \mathrm{~min}$ prior to measurements and kept under a blanket of nitrogen during the course of measurements. 
UV-Vis spectra were recorded on Shimadzu UV-2401PC in dry $\operatorname{MeCN}\left(5 \times 10^{-4} \mathrm{M}\right)$ and reported as $\lambda_{\max } / \mathrm{nm}\left(\varepsilon / \mathrm{M}^{-1} \mathrm{~cm}^{-1}\right)$.

For characterisation of previously reported compounds see the ESI. $\dagger$ All complexes were isolated as a racemic mixture of $\Delta$ and $\Lambda$ enantiomers.

\section{$\left[\mathrm{Ru}(\mathrm{bpy})_{2}(\right.$ eacac $\left.)\right]\left[\mathrm{PF}_{6}\right], 3$}

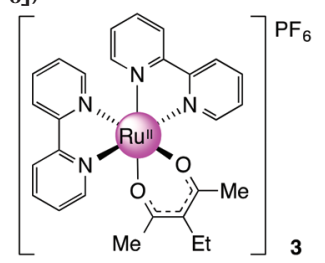

$\mathrm{Ru}(\mathrm{bpy})_{2} \mathrm{Cl}_{2} \cdot 2 \mathrm{H}_{2} \mathrm{O}$ (0.406 g, $0.780 \mathrm{mmol}, 1$ equiv.) was dissolved in degassed $\mathrm{H}_{2} \mathrm{O}-\mathrm{EtOH}(1: 1)$ and heated to $75{ }^{\circ} \mathrm{C}$ for 30 minutes. 3-ethyl-2,4-pentanedione (eacac, $0.100 \mathrm{~g}$, $0.780 \mathrm{mmol}, 1.5$ equiv.) was added to the solution followed by $t$-BuOK $(0.131 \mathrm{~g}, 1.17 \mathrm{mmol}, 1.5$ equiv.). The mixture was then stirred at $75^{\circ} \mathrm{C}$ for $1 \mathrm{~h}$ and cooled to room temperature before $\mathrm{NH}_{4} \mathrm{PF}_{6}$ (0.699 g, $4.29 \mathrm{mmol}, 5.5$ equiv.) was added to precipitate the product. The solid was collected and recrystallised from $\mathrm{CH}_{2} \mathrm{Cl}_{2}$-hexane to give the crude products. The dark solid was then purified using column chromatography (silica gel, $\left.\mathrm{CH}_{2} \mathrm{Cl}_{2}-\mathrm{MeCN} \quad 4: 1\right)$. Yield: $0.05 \mathrm{~g}, \quad 15 \%$. ${ }^{1} \mathrm{H} \quad \mathrm{NMR}$ (400 MHz, DMSO- $\left.d_{6}\right): \delta 0.92(\mathrm{t}, J=6.8 \mathrm{~Hz}, 3 \mathrm{H}), 1.90(\mathrm{~s}, 6 \mathrm{H})$, $2.21(\mathrm{q}, J=6.8 \mathrm{~Hz}, 2 \mathrm{H}), 7.21(\mathrm{~m}, 2 \mathrm{H}), 7.66(\mathrm{~m}, 2 \mathrm{H}), 7.74(\mathrm{~m}$, $2 \mathrm{H}), 7.83(\mathrm{~m}, 2 \mathrm{H}), 8.16(\mathrm{~m}, 2 \mathrm{H}), 8.62(\mathrm{~m}, 4 \mathrm{H}), 8.75(\mathrm{~m}, 2 \mathrm{H})$ ppm. ${ }^{13} \mathrm{C}$ NMR (150.90 MHz, DMSO- $\left.d_{6}\right): \delta 15.32,23.51,27.02$, 109.61, 123.34, 123.45, 125.61, 126.37, 134.60, 136.44, 149.77, 152.73, 157.34, 158.76, 184.99 ppm. MS (ESI): $\mathrm{m} / \mathrm{z} 541.1166$ $\left([\mathrm{M}]^{+}\right.$required 541.1172). Anal. Calcd for $\mathrm{C}_{27} \mathrm{H}_{27} \mathrm{~F}_{6} \mathrm{~N}_{4} \mathrm{O}_{2} \mathrm{PRu}$ : C, 47.30; H, 3.97; N, 8.17; found: C, 46.93; H, 3.94; N, 7.91.

\section{$\left[\operatorname{Ru}(\text { bpy })_{2}(\right.$ dmhd $\left.)\right]\left[\mathbf{P F}_{6}\right], 5$}

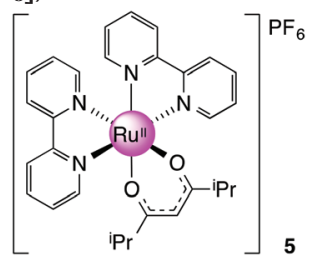

Prepared as for 3 with $0.100 \mathrm{~g}$ ( $0.640 \mathrm{mmol}, 1.2$ equiv.) of 2,6dimethyl-3,5-heptanedione (dmhd). Yield: $0.37 \mathrm{~g}, \quad 60 \%$. ${ }^{1} \mathrm{H}$ NMR (300 MHz, DMSO- $\left.d_{6}\right): \delta 0.58(\mathrm{~d}, J=6.8 \mathrm{~Hz}, 6 \mathrm{H}), 0.79$ $(\mathrm{d}, J=6.8 \mathrm{~Hz}, 6 \mathrm{H}), 2.25(\mathrm{qq}, J=6.8,6.8 \mathrm{~Hz}, 2 \mathrm{H}), 5.34(\mathrm{~s}, 1 \mathrm{H})$, 7.23 (ddd, $J=7.3,7.3,1.3 \mathrm{~Hz}, 2 \mathrm{H}$ ), 7.73 (ddd, $J=7.3,7.3$, $1.3 \mathrm{~Hz}, 2 \mathrm{H}), 7.83-7.90(\mathrm{~m}, 4 \mathrm{H}), 8.16$ (ddd, $J=7.3,7.3,1.5 \mathrm{~Hz}$, $2 \mathrm{H}), 8.50(\mathrm{dd}, J=7.3,1.3 \mathrm{~Hz}, 2 \mathrm{H}), 8.64(\mathrm{dd}, J=7.3,1.3 \mathrm{~Hz}, 2 \mathrm{H})$, 8.75 (dd, $J=7.3,1.5 \mathrm{~Hz}, 2 \mathrm{H}) \mathrm{ppm} .{ }^{13} \mathrm{C}$ NMR $(150.90 \mathrm{MHz}$, DMSO- $\left.d_{6}\right): \delta 19.98,38.18,94.27,123.01,123.21,125.40,126.03$, 134.74, 136.35, 149.63, 153.11, 157.46, 158.75, 192.85 ppm. MS (ESI): $m / z 569.1547$ ([M] $]^{+}$required 569.1485). Anal. Calcd for $\mathrm{C}_{29} \mathrm{H}_{31} \mathrm{~F}_{6} \mathrm{~N}_{4} \mathrm{O}_{2} \mathrm{PRu}$ : C, 48.81; $\mathrm{H}, 4.38$; N, 7.85. Found: C, 48.15; $\mathrm{H}, 4.52 ; \mathrm{N}, 7.70$.

\section{$\left[\mathrm{Ru}(\mathrm{bpy})_{2}(\mathrm{mbpd})\right]\left[\mathrm{PF}_{6}\right], 6$}

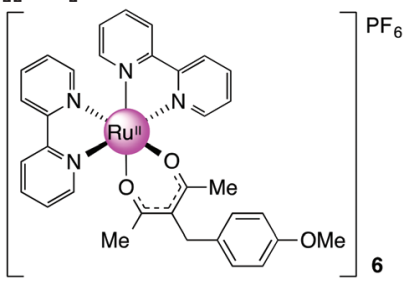

Prepared as for 3 with $0.111 \mathrm{~g}(0.503 \mathrm{mmol}, 1.2$ equiv. $)$ of mbpd. Yield: $0.20 \mathrm{~g}, 53 \%$. ${ }^{1} \mathrm{H}$ NMR (400 MHz, DMSO- $d_{6}$ ): $\delta$ $1.79(\mathrm{~s}, 6 \mathrm{H}), 3.57(\mathrm{~s}, 2 \mathrm{H}), 3.73(\mathrm{~s}, 3 \mathrm{H}), 6.86(\mathrm{~m}, 4 \mathrm{H}), 7.22(\mathrm{~m}$, $2 \mathrm{H}), 7.71(\mathrm{~m}, 2 \mathrm{H}), 7.80-7.88(\mathrm{~m}, 4 \mathrm{H}), 8.22(\mathrm{~m}, 2 \mathrm{H}), 8.67(\mathrm{~m}$, $4 \mathrm{H}), 8.78(\mathrm{~m}, 2 \mathrm{H}) \mathrm{ppm} .{ }^{13} \mathrm{C}$ NMR $\left(100.64 \mathrm{MHz}, \mathrm{DMSO}-d_{6}\right): \delta$ $27.56,34.70,54.99,106.26,113.76,123.38,123.44,125.57$, 126.37, 128.03, 133.26, 134.64, 136.51, 149.74, 152.79, 157.28, 157.36, 158.68, 185.82 ppm. MS (ESI): $m / z 633.1420\left([\mathrm{M}]^{+}\right.$ required 633.1434). Anal. Calcd for $\mathrm{C}_{33} \mathrm{H}_{31} \mathrm{~F}_{6} \mathrm{~N}_{4} \mathrm{O}_{3} \mathrm{PRu}$ : $\mathrm{C}$, 50.97; H, 4.02, N, 7.20. Found: C, 50.34; H, 4.04; N, 7.24.

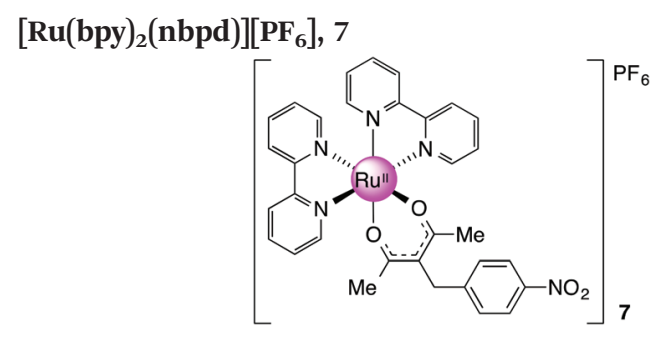

Prepared as for 3 with $0.113 \mathrm{~g}$ ( $0.480 \mathrm{mmol}, 1$ equiv.) of nbpd. Yield: $0.20 \mathrm{~g}, 27 \% .{ }^{1} \mathrm{H}$ NMR (300 MHz, DMSO- $\left.d_{6}\right): \delta 1.79(\mathrm{~s}$, $6 \mathrm{H}), 3.81(\mathrm{~s}, 2 \mathrm{H}), 7.23(\mathrm{~m}, 2 \mathrm{H}), 7.28(\mathrm{~m}, 2 \mathrm{H}), 7.72(\mathrm{~m}, 2 \mathrm{H})$, $7.84-7.88(\mathrm{~m}, 4 \mathrm{H}), 8.16(\mathrm{~m}, 2 \mathrm{H}), 8.23(\mathrm{~m}, 2 \mathrm{H}), 8.65(\mathrm{~m}, 2 \mathrm{H})$, $8.71(\mathrm{~m}, 2 \mathrm{H}), 8.78(\mathrm{~m}, 2 \mathrm{H}) \mathrm{ppm} .{ }^{13} \mathrm{C} \mathrm{NMR}(100.64 \mathrm{MHz}$, DMSO- $\left.d_{6}\right): \delta 27.74,35.82,105.25,123.42,123.46,123.52$, 125.61, 126.49, 128.39, 134.73, 136.65, 145.84, 149.77, 150.49, 152.85, 157.29, 158.68, 185.96 ppm. MS (ESI): $m / z 648.1188$ $\left([\mathrm{M}]^{+}\right.$required 648.1179). Anal. Calcd for $\mathrm{C}_{32} \mathrm{H}_{28} \mathrm{~F}_{6} \mathrm{~N}_{5} \mathrm{O}_{4} \mathrm{PRu}: \mathrm{C}$, 48.49; H, 3.56, N, 8.84. Found: C, 47.85; H, 3.53; N, 8.80.

$\mathrm{Ru}\left(\text { acac- }-\mathrm{NO}_{2}\right)_{3}, 9$

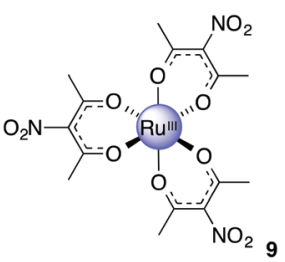

Acetic anhydride $(30 \mathrm{~mL})$ was added to finely ground $\mathrm{Cu}$ $\left(\mathrm{NO}_{3}\right)_{2} \cdot 3 \mathrm{H}_{2} \mathrm{O}(2.35 \mathrm{~g}, 9.73 \mathrm{mmol})$ to give a light blue suspension. The contents were stirred at $0{ }^{\circ} \mathrm{C}$ for $15 \mathrm{~min}$ after the flask was fitted with a calcium chloride drying tube. $8(1.20 \mathrm{~g}$, $3.01 \mathrm{mmol}$ ) was added to the cold deep blue solution. The mixture was stirred at $0{ }^{\circ} \mathrm{C}$ for $2 \mathrm{~h}$ and a further $2 \mathrm{~h}$ at room temperature. Ice (100 g), deionised water (100 g) and anhydrous sodium acetate $(2.14 \mathrm{~g}, 26.1 \mathrm{mmol})$ were added to the now reddish brown mixture. The colour immediately turned greenish blue. The solution was left to stir for $18 \mathrm{~h}$. The contents 
were filtered to give bright red powder. The solid was washed with water to give product as a bright red powder. Yield: $1.12 \mathrm{~g}, 70 \%$. ${ }^{1} \mathrm{H}$ NMR (400 $\mathrm{MHz}, \mathrm{CDCl}_{3}$ ): $\delta-3.55$ (s, 18H) ppm. MS (ESI): $m / z 556.9813\left([\mathrm{M}+\mathrm{Na}]^{+}\right.$required 556.9826). Anal. Calcd for $\mathrm{C}_{15} \mathrm{H}_{18} \mathrm{~N}_{3} \mathrm{O}_{12} \mathrm{Ru}$ : C, 33.78; H, 3.40; N, 7.88. Found: C, 33.01; H, 3.54; N, 7.65.

$\mathrm{Ru}\left(\mathrm{NO}_{2} \text {-acac }\right)_{2}($ bpy $), 15$

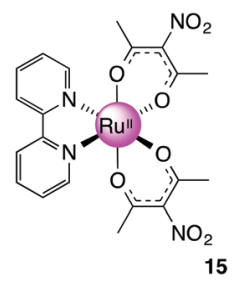

(a) Compound 9 (0.574 g, $1.08 \mathrm{mmol})$ was stirred in EtOH with activated zinc dust $(0.5 \mathrm{~g})$ for $1 \mathrm{~h}$, during which time the colour changed from bright red to brown. MeCN ( $5 \mathrm{~mL}$ ) was added to the brown mixture and refluxed for $4 \mathrm{~h}$. The mixture was filtered through a bed of celite on which a brown layer remained. The crude product was subjected to silica gel column chromatography to first elute unreacted 9 with $\mathrm{CH}_{2} \mathrm{Cl}_{2}$ followed by EtOAc to flush the product out from the column as an orange fraction. Solvent was removed to give the title product as an orange solid. Yield: $0.46 \mathrm{~g}, 92 \% .{ }^{1} \mathrm{H}$ NMR (400 MHz, DMSO- $\left.d_{6}\right): \delta 2.09(\mathrm{~s}, 6 \mathrm{H}), 2.11(\mathrm{~s}, 6 \mathrm{H}), 2.73(\mathrm{~s}, 6 \mathrm{H})$ ppm. ${ }^{13} \mathrm{C}$ NMR (100.64 MHz, DMSO- $\left.d_{6}\right): \delta 3.83,26.59,26.83$, 128.46, 139.13, 183.15, 184.52 ppm. MS (ESI): $\mathrm{m} / \mathrm{z} 495.0052$ $\left([\mathrm{M}+\mathrm{Na}]^{+} 495.0060\right)$.

(b) The $\mathrm{Ru}\left(\text { acac- } \mathrm{NO}_{2}\right)_{2}(\mathrm{MeCN})_{2}$ intermediate isolated in (a) $(0.200 \mathrm{~g}, 0.424 \mathrm{mmol})$ and bpy $(0.0660 \mathrm{~g}, 0.423 \mathrm{mmol})$ were added to a Schlenk flask followed by EtOH $(\sim 15 \mathrm{~mL})$. The reaction was refluxed for $5 \mathrm{~h}$ before solvent was removed under reduced pressure to give a dark brown solid. The solid was purified by column chromatography (silica gel, $\mathrm{MeCN}-\mathrm{CH}_{2} \mathrm{Cl}_{2}$ $1: 5)$ to give a dark brown solid. Yield: $0.030 \mathrm{~g}, 13 \% .{ }^{1} \mathrm{H}$ NMR $\left(500 \mathrm{MHz}, \mathrm{DMSO}-d_{6}\right): \delta 1.76(\mathrm{~s}, 6 \mathrm{H}), 2.28(\mathrm{~s}, 6 \mathrm{H}), 7.52(\mathrm{~m}, 2 \mathrm{H})$, $7.90(\mathrm{~m}, 2 \mathrm{H}), 8.59(\mathrm{~m}, 2 \mathrm{H}), 8.68(\mathrm{~m}, 2 \mathrm{H}) \mathrm{ppm} .{ }^{13} \mathrm{C} \mathrm{NMR}$ (150.90 MHz, DMSO- $d_{6}$ ): 26.57, 27.11, 122.74, 125.21, 128.44, 134.66, 152.07, 159.82, 182.14, 184.49 ppm. MS (ESI): $m / z$ $569.0209\left([\mathrm{M}+\mathrm{Na}]^{+}\right.$required 569.0217). Anal. Calcd for $\mathrm{C}_{20} \mathrm{H}_{20} \mathrm{~N}_{4} \mathrm{O}_{8} \mathrm{Ru}$ : C, 44.04; $\mathrm{H}$ 3.70; N 10.27. Found: C, 44.17; $\mathrm{H}, 3.77$; N, 10.04 .

\section{Acknowledgements}

Financial support from the University of New South Wales and the Australian Research Council (LP100200593) is gratefully acknowledged. We also would like to thank staff of the NMR Facility, Mark Wainwright Analytical Centre, UNSW for their assistance.

\section{Notes and references}

1 N. Metzler-Nolte and M. Salmain, in Ferrocenes, John Wiley \& Sons, Ltd, 2008, pp. 499-639, DOI: 10.1002/ 9780470985663.ch13.

2 D. R. van Staveren and N. Metzler-Nolte, Chem. Rev., 2004, 104, 5931-5986.

3 M. F. R. Fouda, M. M. Abd-Elzaher, R. A. Abdelsamaia and A. A. Labib, Appl. Organomet. Chem., 2007, 21, 613-625.

4 M. Kind and C. Woell, Prog. Surf. Sci., 2009, 84, 230-278.

5 I. Willner and E. Katz, Angew. Chem., Int. Ed., 2000, 39, 1181-1218.

6 Y. Wan, Y. Su, X. Zhu, G. Liu and C. Fan, Biosens. Bioelectron., 2013, 47, 1-11.

7 S. Martic, M. Labib, P. O. Shipman and H.-B. Kraatz, Dalton Trans., 2011, 40, 7264-7290.

8 T. Joshi, G. J. Barbante, P. S. Francis, C. F. Hogan, A. M. Bond, G. Gasser and L. Spiccia, Inorg. Chem., 2012, 51, 3302-3315.

9 S. M. Khor, G. Liu, J. R. Peterson, S. G. Iyengar and J. J. Gooding, Electroanalysis, 2011, 23, 1797-1804.

10 R. Prins, A. R. Korwagen and A. G. T. G. Kortbeek, J. Organomet. Chem., 1972, 39, 335-344.

11 D. Ge and R. Levicky, Chem. Commun., 2010, 46, 71907192.

12 R. Prins, A. R. Korswagen and A. G. T. G. Kortbeek, J. Organomet. Chem., 1972, 39, 335-344.

13 H. Ju and D. Leech, Phys. Chem. Chem. Phys., 1999, 1, 15491554.

14 S. M. Zakeeruddin, D. M. Fraser, M. K. Nazeeruddin and M. Grätzel, J. Electroanal. Chem., 1992, 337, 253-283.

15 D. M. Fraser, S. M. Zakeeruddin and M. Grätzel, J. Electroanal. Chem., 1993, 359, 125-139.

16 C. Zhang, T. Haruyama, E. Kobatake and M. Aizawa, Anal. Chim. Acta, 2000, 408, 225-232.

17 S. Warren, T. McCormac and E. Dempsey, Bioelectrochemistry, 2005, 67, 23-35.

18 T. V. Federova, A. S. Vilesov, S. A. Kurzeev, E. V. Stepanova, E. O. Landesman and O. V. Koroleva, Appl. Biochem. Microbiol., 2006, 42, 550-557.

19 E. V. Ivanova, V. S. Sergeeva, J. Oni, C. Kurzawa, A. D. Ryabov and W. Schuhmann, Bioelectrochemistry, 2003, 60, 65-71.

20 I. L. Medintz, D. Farrell, K. Susumu, S. A. Trammell, J. R. Deschamps, F. M. Brunel, P. E. Dawson and H. Mattoussi, Anal. Chem., 2009, 81, 4831-4839.

21 M.-Y. Wei, S.-D. Wen, X.-Q. Yang and L.-H. Guo, Biosens. Bioelectron., 2009, 24, 2909-2914.

22 N. A. Yusof, Asian J. Chem., 2011, 23, 1153-1157.

23 W.-W. Yang, Y.-W. Zhong, S. Yoshikawa, J.-Y. Shao, S. Masaoka, K. Sakai, J. Yao and M. Haga, Inorg. Chem., 2012, 51, 890-899.

24 R. Cerón-Camacho, S. Hernández, R. L. Lagadec and A. D. Ryabov, Chem. Commun., 2011, 47, 2823-2825.

25 H. Weizman and Y. Tor, J. Am. Chem. Soc., 2002, 124, 15681569. 
26 M. Vrábel, M. Hocek, L. Havran, M. Fojta, I. Votruba, B. Klepetářá, R. Pohl, L. Rulíšek, L. Zendlová, P. Hobza, I. Shih, E. Mabery and R. Mackman, Eur. J. Inorg. Chem., 2007, 1752-1769.

27 J. J. Rack, E. S. Krider and T. J. Meade, J. Am. Chem. Soc., 2000, 122, 6287-6288.

28 A. Endo, M. Kajitani, M. Mukaida, K. Shimizu and G. P. Sato, Inorg. Chim. Acta, 1988, 150, 25-34.

29 N. L. Frank and T. J. Meade, Inorg. Chem., 2003, 42, 10391044.

30 M. Haga, T. Matsumura-Inoue, K. Shimizu and G. P. Satô, J. Chem. Soc., Dalton Trans., 1989, 371-373.

31 L. Wolf, E. Butter and H. Weinelt, Z. Anorg. Allg. Chem., 1960, 306, 87-93.

32 A. Endo, K. Shimizu and G. P. Satô, Chem. Lett., 1985, 1985, 581-584.

33 S. Munery, J. Jaud and J. Bonvoisin, Inorg. Chem. Commun., 2008, 11, 975-977.

34 M. S. Chan and A. C. Wahl, J. Phys. Chem., 1985, 89, 58295831.

35 S. Munery, J. Jaud and J. Bonvoisin, Inorg. Chem. Commun., 2008, 11, 975-977.

36 J.-H. Olivier, J. Harrowfield and R. Ziessel, Chem. Commun., 2011, 47, 11179-11188.

37 J. P. Collman, Angew. Chem., Int. Ed., 1965, 4, 132-138.

38 J. P. Collman, R. A. Moss, H. Maltz and C. C. Heindel, J. Am. Chem. Soc., 1961, 83, 531-534.

39 R. W. Kluiber, J. Am. Chem. Soc., 1960, 82, 4839-4842.

40 P. R. Singh and R. Sahai, Aust. J. Chem., 1967, 20, 639-648.

41 P. R. Singh and R. Sahai, Aust. J. Chem., 1967, 20, 649-655.

42 J. P. Collman, R. L. Marshall, W. L. I. Young and S. D. Goldby, Inorg. Chem., 1962, 1, 704-710.

43 I. R. Baird, S. J. Rettig, B. R. James and K. A. Skov, Can. J. Chem., 1999, 77, 1821-1833.

44 A. K. Gupta and R. K. Poddar, Indian J. Chem. Sect. A: Inorg., Bio-inorg., Phys., Theor. Anal. Chem., 2000, 39, 457-460.
45 T. Kobayashi, Y. Nishina, K. Shimizu and G. P. Satô, Chem. Lett., 1988, 1137-1140.

46 R. A. Krause, Inorg. Chim. Acta, 1977, 22, 209-213.

47 A. M. El-Hendawy, A. H. Al-Kubaisi and H. A. Al-Madfa, Polyhedron, 1997, 16, 3039-3045.

48 A. M. El-Hendawy, A. H. Al-Kubaisi and H. A. Al-Madfa, Polyhedron, 1997, 16, 3039-3045.

49 E. Eskelinen, M. Haukka, T.-J. J. Kinnunen and T. A. Pakkanen, J. Electroanal. Chem., 2003, 556, 103108.

50 N. G. Tsierkezos, J. Solution Chem., 2007, 36, 289-302.

51 A. Endo, Y. Hoshino, K. Hirakata, Y. Takeuchi, K. Shimizu, Y. Furushima, H. Ikeuchi and G. P. Satô, Bull. Chem. Soc. Jpn., 1989, 62, 709-716.

52 H. Ikeuchi, K. Naganuma, M. Ichikawa, H. Ozawa, T. Ino, M. Sato, H. Yonezawa, S. Mukaida, A. Yamamoto and T. Hashimoto, J. Solution Chem., 2007, 36, 1243-1259.

53 A. Endo, Bull. Chem. Soc. Jpn., 1983, 56, 2733-2738.

54 C. Hansch, A. Leo and R. W. Taft, Chem. Rev., 1991, 91, 165-195.

55 G. S. Patterson and R. H. Holm, Inorg. Chem., 1972, 11, 2285-2288.

56 S. J. Slattery, W. D. Bare, D. L. Jameson and K. A. Goldsby, J. Chem. Soc., Dalton Trans., 1999, 1999, 1347-1352.

57 A. J. L. Pombeiro, Eur. J. Inorg. Chem., 2007, 14731482.

58 A. B. P. Lever, Inorg. Chem., 1990, 29, 1271-1285.

59 A. Wu, J. Masland, R. D. Swartz, W. Kaminsky and J. M. Mayer, Inorg. Chem., 2007, 46, 11190-11201.

60 G. M. Bryant, J. E. Fergusson and H. K. J. Powell, Aust. J. Chem., 1971, 24, 257-273.

61 Y. Takahashi, H. Arakawa, H. Sugihara, K. Hara, A. Islam, R. Katoh, Y. Tachibana and M. Yanagida, Inorg. Chim. Acta, 2000, 310, 169-174.

62 K. Kuroda, K. Yoshitani, K. Kunigita, Y. Kamiiba and K. Watanabe, Bull. Chem. Soc. Jpn., 1976, 49, 24452450 . 